\title{
Early Discriminatory Diagnosis of Dementia with Lewy Bodies
}

\author{
The Emerging Role of CSF and Imaging Biomarkers
}

\author{
Dag Aarsland ${ }^{a, c}$ Martin Kurz ${ }^{a}$ Mona Beyer ${ }^{b}$ Kolbjørn Bronnick ${ }^{a}$ \\ Sabine Piepenstock Nore ${ }^{d}$ Clive Ballard $^{\mathrm{e}}$ \\ ${ }^{a}$ Norwegian Centre for Movement Disorders and bepartment of Radiology, Stavanger University Hospital, \\ Stavanger, and ${ }^{C}$ Institute of Clinical Medicine, University of Bergen, and ${ }^{\mathrm{d}}$ Geriatric section, Haraldsplass Deaconess

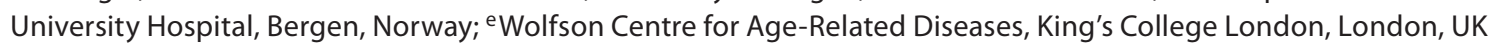

\section{Key Words \\ Dementia with Lewy bodies, early diagnosis • \\ Cerebrospinal fluid $\cdot$ Imaging biomarkers}

\begin{abstract}
Background: The clinical diagnostic criteria for dementia with Lewy bodies (DLB) have a low sensitivity, and there are no generally accepted biomarkers to distinguish DLB from other dementias. Our aim was to identify biomarkers that may differentiate DLB from Alzheimer's disease (AD). Method: We performed a systematic literature search for studies of EEG, imaging techniques and genetic and CSF markers that provide sensitivity and specificity in the identification of DLB. Results: The best evidence was for scintigraphy of the striatal dopamine transporter system using FP-CITSPECT. Several small scintigraphy studies of cardiovascular autonomic function using metaiodobenzylguanidine SPECT have reported promising results. Studies exploring innovative techniques based on CSF have reported interesting findings for the combination of amyloid $\beta(a \beta)$ isoforms as well as $\alpha$-synuclein, and there are interesting results emerging from preliminary studies applying proteomic techniques. Data from studies using structural MRI, perfusion SPECT, genetics and EEG studies show differences between DLB and $A D$ but only at a group level. Conclusion: Several potential
\end{abstract}

\section{KARGER \\ Fax +4161306 1234 \\ E-Mail karger@karger.ch}

www.karger.com

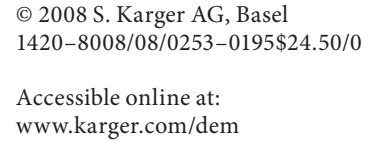

biomarkers for the differential diagnosis of probable DLB and AD have shown good diagnostic accuracy in the research setting. Data from large multicentre studies and from studies with autopsy confirmation exist for scintigraphy of the dopamine transporter system. Future studies should explore its value in possible DLB and for clinical management and health economics.

Copyright $\odot 2008$ S. Karger AG, Basel

\section{Definition and Epidemiology of Dementia with Lewy Bodies}

Dementia with Lewy bodies (DLB) is defined clinically as dementia accompanied by the following core features: fluctuating cognition and consciousness, spontaneous features of parkinsonism and visual hallucinations. The main pathological features are Lewy bodies or Lewy neurites in brain stem nuclei, limbic structures and neocortex. Lewy bodies are intraneuronal cytoplasmic, eosinophilic and spherical inclusion bodies composed of $\alpha$-synuclein and ubiquitin. They form the altered neurofilaments that accumulate after abnormal cleavage and phosphorylation of $\alpha$-synuclein. Neurochemically, DLB is characterised by loss of cortical cholinergic markers and nigrostriatal dopamine loss [1]. 
Although DLB was once considered rare, there is now widespread agreement that the condition is the second most common form of neurodegenerative dementia [Alzheimer's disease (AD) being the most common] and that it accounts for $10-20 \%$ of dementia cases seen in pathological dementia cohorts [1]. In 1 study, based on an unselected autopsy cohort, as many as $41 \%$ of individuals with dementia had a pathological diagnosis of DLB [2]. However, there is little robust epidemiological evidence on which to base estimates of DLB frequency, the available studies being limited mainly by inadequate definition of the source population and selection bias due to hospital-based sampling. The few population-based prevalence studies that have been reported generally lack a rigorous methodology for DLB diagnosis.

A recent systematic review reported that the prevalence of DLB was $0-5 \%$ in the general population and $0-30 \%$ in dementia cohorts; the DLB incidence (1 study only) was $0.1 \%$ per year in the general population and $3.2 \%$ per year among all new dementia cases [3]. Of note, dementia associated with Parkinson's disease (PD), a condition with similar clinical phenotype and brain changes as DLB [4], accounts for 3-4\% of the total dementia population [5]. The relationship between dementia associated with PD and DLB is not yet established, and the current clinical distinction is based on the relative timing of parkinsonism and dementia; patients with dementia that develops before or within a year of the onset of parkinsonism are diagnosed as having DLB, whereas those who develop dementia a year or more after the onset of parkinsonism are diagnosed as having dementia associated with PD [4].

\section{Why Is DLB Difficult to Diagnose?}

Most studies based on the 1996 consensus criteria for clinical diagnosis of DLB [6] have reported a high specificity $(80-100 \%)$ but a low sensitivity $(20-60 \%)$ [1]; i.e. if a diagnosis of DLB was made, it was usually correct, but many cases were missed. The revised clinical consensus criteria, published in 2005, give greater diagnostic weight to clinical features suggestive of DLB, such as severe neuroleptic sensitivity and REM sleep disorder [7], but their sensitivity and specificity have not yet been explored.

DLB can be difficult to diagnose in the community because patients with early-stage disease usually present with attention, motor or psychiatric changes rather than reduced memory function, and the diagnosis is often missed on memory-based screening. Differential diagno- sis of DLB is even more difficult in the later stages of the disease, when its presentation resembles that of other late-stage dementia types.

Furthermore, there is a lack of valid and reliable methods for assessing the core clinical features by which DLB is usually identified. Fluctuating consciousness can be particularly hard to diagnose reliably, with wide variations in the reported frequency and in the findings of different assessors looking at the same patients [8]. The assessment scales now available for neurodegenerative diseases offer improved psychometric properties [9] and include reliable tools for the assessment of parkinsonism, such as the Unified Parkinson's Disease Rating Scale [10], but several have a low inter-assessor reliability when applied to patients with dementia [11]. A modified version of the Unified Parkinson's Disease Rating Scale motor subscale has been developed for patients with DLB [12] but is not yet in widespread use. There is clearly a need for improved methods for assessing the key clinical features of DLB, to improve the accuracy of clinical diagnosis.

Finally, the brain pathology in patients with DLB is heterogeneous, leading to variations in the clinical phenotype. For example, the classical clinical features of DLB may be less prominent in patients with DLB, who have a greater burden of neocortical Alzheimer pathology, compared to those with pure Lewy body pathology [13]. Likewise, the presence of neurofibrillary tangles leads to a clinical presentation more typical of $\mathrm{AD}$ than $\mathrm{DLB}$ - i.e. a more classical amnestic syndrome in clear consciousness and less pronounced visual hallucinations or parkinsonism [13].

\section{Why Is Early Discrimination of DLB Important?}

A correct early diagnosis of dementia helps the physician to assess the individual's prognosis and make informed decisions on the best course of management [14]. It can be reassuring for patients and caregivers to know that the diverse range of symptoms, affecting modalities such as cognitive function, psychiatric health, motor function, sleep, attention and autonomy, are all part of a dementia syndrome due to a brain disease. A diagnosis of DLB also prompts the physician to check for additional DLB-specific symptoms that are not generally considered in other forms of dementia - e.g. visual hallucinations, which may not be voluntarily reported by the patient.

There is emerging evidence that DLB differs from AD in the disease course and treatment response experienced 
by patients; thus early differentiation between the 2 forms of dementia is important for effective and safe management. Most importantly, people with DLB are at high risk of severe reactions to antipsychotic drugs [15]. Care should be taken when prescribing antipsychotics for any patient with dementia because of the possibility of an adverse event, but the risk of developing severe neuroleptic sensitivity reactions to typical and atypical antipsychotics, with motor and cognitive impairment, is much higher in DLB than in AD [16]. In addition, some patients with DLB may respond to dopaminergic treatment for parkinsonism [17], which has not been reported for $\mathrm{AD}$, and which may be withheld in the absence of an accurate diagnosis.

Given the many different clinical symptoms of DLB, it is not surprising that patients with this type of dementia have more functional impairment [18] and a greater impairment of quality of life [19] than people with $\mathrm{AD}$, even when the level of dementia is similar. Few adequately designed studies have compared the longitudinal disease course in DLB with that of other dementias. A recent clinico-pathological longitudinal study has reported a more malignant disease course, with a higher mortality rate and a trend towards shorter time to nursing home admission, in DLB compared to AD [20]. Similarly, the findings of a health-economics study have shown that the annual care costs are more than $100 \%$ higher for patients with DLB than for those with AD, despite a similar level of cognitive impairment in the 2 groups, the difference being driven mainly by a higher rate of institutionalisation for DLB [21]. Thus, compared to people with AD, patients with DLB suffer more, are more costly to society and need more frequent and careful follow-up.

Finally, as the underlying pathophysiological mechanisms leading to $\alpha$-synuclein aggregation and Lewy body degeneration are unravelled [22], there is growing interest in developing disease-modifying drugs aimed at these pathological processes. Clinical and biomarker measurements can, in addition to their role in assessing disease progression, aid in the development and assessment of novel drug therapies.

\section{Potential Biomarkers for DLB}

The advantages of early diagnosis, combined with suboptimal clinical diagnostic accuracy, highlight the need for a valid biological marker for DLB. The objective of this study therefore was to review the literature to identify potential biomarkers that may distinguish DLB from
AD. We searched the MEDLINE database, using the phrase 'dementia with Lewy bodies' combined with: biomarkers (30 papers), EEG (17), imaging (109), MRI (47), SPECT (49), metaiodobenzylguanidine (MIBG) (16), genetics (134) and cerebrospinal fluid (CSF) (28). In addition, we searched reference lists from the papers identified and from relevant book chapters and proceedings from recent meetings. We read the abstracts of studies reporting on potential biomarkers in DLB and full papers reporting original studies of potential biomarkers. Sensitivity and specificity data, where provided, were recorded.

\section{Role of EEG}

EEG findings may be helpful in the diagnosis of people with dementia; for example, slowing of the EEG rhythm is a frequent finding in $\mathrm{AD}$ and other dementias. Spectral analysis of the EEG may be performed after transformation of the EEG from the time domain to the frequency domain, using the Fourier method, allowing determination of the exact amplitude or power values of different frequency bands. EEG coherence describes the similarity of electric function between 2 or more cortical sites.

Research on the differential diagnostic properties of EEG in dementia is sparse, and none of the published studies reports information about diagnostic sensitivity or specificity. At best, statistical differences between DLB and other patient groups or healthy controls are reported.

Several studies, based on small numbers of patients (some with inadequately described statistics), have shown more slowing of EEG rhythm in DLB than in AD. One study reported slowing of posterior EEG background rhythm and frontal dominant slow-wave burst patterns [23]. Another found frontal intermittent rhythmic $\delta$-activity in $70 \%$ of patients with DLB and $22 \%$ of patients with $\mathrm{AD}$ and slowing of background EEG rhythm in $100 \%$ of patients with DLB and $66 \%$ of those with AD [24]. In another study, patients with DLB confirmed by autopsy showed a greater tendency towards slowing of both dominant and non-dominant EEG rhythm compared to patients with $\mathrm{AD}$, and they more often had temporal slow-wave transients, which correlated with episodes of loss of consciousness [25]. In contrast, 2 studies reported no significant EEG differences between DLB and $\operatorname{AD}[26,27]$, including the largest study, which involved 34 and 28 patients with DLB and AD, respectively.

There have been several EEG spectrum studies in DLB using Fourier analysis (quantitative EEG). Kai et al. [28], 
in a study of power spectra and coherence, found that patients with $\mathrm{DLB}$, but not those with $\mathrm{AD}$, had an increased power density of the EEG in the $\delta$ - and $\theta$-bands and a higher intrahemispheric coherence in fronto-temporocentral regions in the same bands. One study of the quantitative EEG correlates of fluctuating cognition showed a significantly higher variability in the slow $\delta$-wave domain in patients with DLB than in those with AD or in healthy controls [29]. In another study, the variability in mean EEG frequency over 90-second intervals was larger in DLB than in AD or in healthy controls [30].

In summary, although EEG differences between DLB and $\mathrm{AD}$ have been reported, there is no evidence indicating sensitivity and specificity values, and thus EEG cannot serve as a biomarker for differentiating DLB and AD.

\section{Genetic Testing}

Exciting recent discoveries of causative and susceptibility genes for $\mathrm{AD}$, fronto-temporal dementia and $\mathrm{PD}$ have raised the possibility of genetic testing for the differential diagnosis of dementia. Several mutations have been identified that lead to rare cases of familial PD [31] and $\mathrm{AD}$ [32]. The overlap of brain pathology between $\mathrm{DLB}$ and both $\mathrm{AD}$ and $\mathrm{PD}$ indicates a shared underlying pathophysiology, but the genetic basis of DLB has rarely been studied. However, the familial aggregation of DLB provides some evidence of genetic involvement in the development of the disease [33,34].

Many patients with a clinical picture consistent with DLB have shown either mutations in the synuclein gene or positive correlations with the APOE $\varepsilon 3 / 4$ and $\varepsilon 4 / 4$ allele. Interestingly, mutations in the $\alpha$-synuclein gene can lead to Lewy body formation and a phenotype of DLB as well as PD [33]. The argument for $\alpha$-synuclein having a substantial role in DLB is further strengthened by its deposition in Lewy bodies and the fact that the Lewy body score is a diagnostic criterion for the disease [35] and is associated with cognitive decline in PD [36].

Patients carrying $L R R K 2$ mutations show a remarkably varying pathological pattern, ranging from pure degeneration without Lewy bodies to degeneration with widespread Lewy bodies and neurofibrillary $\tau$-positive tangles $[37,38]$. However, the clinical findings in affected individuals are typical for sporadic $\mathrm{PD}$ without major development of dementia [39]. The mechanisms by which mutations in the LRRK2 gene cause PD and the reason why neuropathologic patterns fitting those of DLB are not accompanied by dementia still have to be determined, particularly since LRRK2 could be a component of Lewy bodies in PD and DLB [40].
APOE $\varepsilon 4$ alleles are more common in $\mathrm{AD}$ than in controls and are associated with an earlier age of disease onset [41]. Findings regarding APOE polymorphisms in DLB have so far been inconclusive. Some studies show evidence for more frequent occurrence of e4 alleles in $\mathrm{DLB}$ compared to normal controls but similar to AD, indicating that DLB shares the $A P O E \varepsilon 4$ allele with $\mathrm{AD}$ as a common risk factor, although there may be some differences in the way the e4 allele affects the phenotypic expression of disease $[42,43]$. Others studies, however, have been unable to reproduce this finding and have shown a similar proportion of APOE $\varepsilon 4$ in DLB and controls [44], including a recent study with pathologic confirmation of the diagnosis [20].

Based on these findings, genetic testing is currently not a convenient source of candidate biomarkers for DLB.

\section{CSF and Blood-Based Biomarkers}

Although CSF may be a less appealing source of biomarkers because of the difficulty of obtaining samples, its physiological relationship with the brain makes it particularly interesting. It is well established that reduced concentrations of a $\beta$ peptide, combined with increased total and phosphorylated tau, has a good sensitivity and specificity in differentiating patients with $\mathrm{AD}$ from old people without cognitive impairment and from those with other dementias [45]. However, the potential of CSF biomarkers as a tool to distinguish between DLB and AD has been less well explored. Concentrations of a $\beta$ 1-42 have been reported to be higher in patients with DLB than in aged-matched controls [46], but the majority of sensitivity and specificity studies do not indicate that the levels of CSF a $\beta$ 1-40 or a $\beta$ 1-42 can usefully discriminate between DLB and AD [47]. There are only very limited data on longitudinal change or correlation with key clinical symptoms. One study identified an increase in a $\beta$ with disease duration but did not find an association with Mini Mental State Examination (MMSE) scores [46]. A better understanding of the relationship between a $\beta 1-40$ or a $\beta 1-42$ and clinical symptoms and disease course is essential if these biomarkers are to be of use in differential diagnosis.

Recent studies using innovative techniques to measure other a $\beta$ peptides have produced more promising results. In particular, a novel peptide suggested to represent an oxidised $\alpha$-helical form of a $\beta$ 1-40 (a $\beta$-ox) that may form as a result of the interaction between a $\beta$ peptides and $\alpha$-synuclein was found to be significantly increased in DLB in a pilot study [48]. The findings were 
similar in a subsequent validation study in a larger sample [49], in which the level of a $\beta$-ox was found to differentiate DLB from controls without dementia with a sensitivity of $88 \%$ and a specificity of $83 \%$. Discrimination between DLB and other dementias was less accurate (sensitivity $=88 \%$, specificity $=70 \%$ ). Differentiation between DLB and AD was not reported. These findings are based on optimal ratios from post-hoc analyses and probably overestimate the discriminatory value of the $\mathrm{a} \beta$ peptide in question.

Other potentially interesting a $\beta$ isoforms include $a \beta$ $1-37$ and a $1-38[48,49]$.

Differences in total tau [50] and phosphorylated tau $[47,50,51]$ appear to be more robust in distinguishing $\mathrm{DLB}$ and $\mathrm{AD}$ on a group basis, but the sensitivity of discrimination is still in the $70-80 \%$ range, and the large variability renders tau and phosphorylated tau less useful as potential diagnostic markers for individual patients [52].

Although $\alpha$-synuclein, the key protein in the pathogenesis of DLB and PD, is predominantly intracellular, extracellular forms have been identified, including in CSF and plasma [53]. Reduced levels of $\alpha$-synuclein in the CSF have been associated with increasing severity of parkinsonism in patients with PD [54], and preliminary findings have shown a significant increase in $\alpha$-synuclein oligomers in plasma in patients with PD compared with controls [53]. In addition, initial studies indicate that people with DLB have lower CSF levels of $\alpha$-synuclein than controls or people with $\mathrm{AD}[55,56]$, but since these papers have not yet been reported in full, the sensitivity and specificity of CSF $\alpha$-synuclein in the diagnostic discrimination of DLB and AD remain unclear. There are no direct assessments of $\alpha$-synuclein in plasma from DLB patients.

The emerging body of work on $\alpha$-synuclein is exciting, but further studies are needed to confirm the specificity of the antibodies, investigate alterations in specific isoforms, establish the pattern of changes in $\alpha$-synuclein dimers and oligomers and elucidate the relationship with key clinical features.

Other candidate markers include indices of oxidative stress [57] and antioxidants [58], but the studies are contradictory and therefore difficult to interpret. A smaller body of work has suggested the potential utility of homocysteine [59] or mitochondrial markers [60], but the data are very preliminary. Autopsy and microarray studies have begun to highlight other potential biomarkers, such as heat shock proteins [61], but their potential value is not yet clear.
The development of genomics and proteomics allows identification of a large number of proteins and has the potential to accelerate the discovery of biomarkers for DLB and other neurodegenerative diseases. High sensitivity at $95 \%$ specificity has been reported in the first study to use proteomics to identify the simultaneous change of a large number of proteins in patients with DLB [62]. The authors identified more than 1,500 proteins in CSF from patients with AD, PD and DLB and controls. For each disease, more than 300 proteins were identified that differed from those in controls, of which about 100 were unique for each disease. Eight candidate proteins were selected for further testing as disease markers. Single markers with adequate sensitivity and specificity were found for AD and PD but not for DLB. However, the ability to distinguish between diseases increased when the markers were combined, 2 at a time, and became significant for DLB (sensitivity $=50 \%$ at $95 \%$ specificity) as well as for $\mathrm{AD}$ and $\mathrm{PD}$. The potential value of this observation needs to be investigated further after the individual proteins have been identified and, given the small number of patients with DLB in the study, the findings need to be interpreted with caution. Thus, although currently not adequate for use, promising new techniques based on CSF protein analysis are emerging that may develop into useful biomarkers for the differentiation of DLB and $\mathrm{AD}$.

DLB is a heterogeneous disease, involving several neurodegenerative processes, so it seems unlikely that 1 single biomarker will adequately distinguish it from other dementias. Further work is needed to understand how alterations in biomarkers relate to pathological changes in the brain and to clinical symptoms and to develop models based upon combinations of biomarkers that best characterise the profile of DLB.

\section{Imaging Techniques}

Structural MRI

Neuroimaging investigations, both structural (CT and MRI) and functional (SPECT and PET), may be helpful in the diagnosis of dementia, and emerging evidence suggests that some imaging techniques may be helpful in the differential diagnosis of DLB.

Dementia studies using structural MRI demonstrate patterns of cortical and subcortical atrophy and whitematter lesions. A characteristic pattern of atrophy has been identified in $\mathrm{AD}$, with marked atrophy of the hippocampus and medial temporal lobe [63]. Among the few MRI studies involving patients with DLB, significant differences have been reported between DLB and AD; the 
typical finding is preservation of the hippocampus and medial temporal lobe volume in DLB in comparison with $\mathrm{AD}$ [64-66]. These differences are based on group studies and cannot reliably distinguish DLB from AD on an individual level, demonstrated by the low reported sensitivity (40\%) [65]. Other MRI changes, such as atrophy of the putamen [67] and the basal forebrain [68, 69], wholebrain atrophy [66], white-matter lesions and rates of progression of whole-brain atrophy [70], are even less specific and not helpful in the diagnosis.

A recent study - the largest to date in terms of patient numbers - used an automated voxel-based technique without specifying an a priori area of interest and found a signal pattern in DLB, involving focal atrophy of several areas, including the substantia innominata, hypothalamus and dorsal midbrain, indicating that this pattern of atrophy combined with a relatively preserved medial temporal lobe was suggestive of DLB [71]. Again, these were group data and there was substantial overlap between individuals in the AD and DLB groups. Sensitivity and specificity values were not reported. Thus, although it is useful in the diagnostic work-up of patients with dementia, structural MRI cannot yet be considered a good biomarker of DLB versus AD.

\section{Perfusion SPECT}

SPECT studies, with markers such as ${ }^{99} \mathrm{mTc}-\mathrm{HMPAO}$, can be used to assess regional cerebral blood flow as a measure of cortical function. A characteristic pattern of occipital and parietal hypoperfusion - the so-called horseshoe sign - has been demonstrated in DLB [72]. This image differs from the pattern of reduced flow in parieto-temporal areas typically seen in $\mathrm{AD}$.

Relatively few studies have explored the accuracy of SPECT in the identification of individual patients with DLB. In 1 early study, the diagnostic accuracy was relatively low, with sensitivity and specificity values of about $65 \%$ [72], while a more recent report has suggested higher rates of both sensitivity (81\%) and specificity (85\%) [73]. A diagnostic strategy combining SPECT and MMSE performance has produced a sensitivity of $81 \%$ and a specificity of $85 \%$ [74], although less encouraging results have also been reported [75].

Overall, the studies available suggest that occipital hypoperfusion on SPECT should raise suspicion of DLB, and some recent studies have reported good diagnostic precision. Large-scale multicentre studies are needed to establish if perfusion SPECT should be recommended as a biomarker for DLB. Similarly, fluorodeoxyglucose-PET studies have demonstrated reductions in occipital and parietal glucose metabolism [76], but the technique is not yet available in many of the centres where dementia is diagnosed.

\section{Cardiac Scintigraphy}

Cardiovascular autonomic dysfunction is particularly common in DLB [77], and scintigraphy with ${ }^{123}$ I-MIBG enables the quantification of post-ganglionic cardiac sympathetic innervation [78].

MIBG scintigraphy was introduced as a diagnostic tool for the involvement of the autonomous nervous system in diseases such diabetic neuropathy and later in patients with PD (including early-stage disease [79]) and autonomic failure. Several studies using ${ }^{123}$ I-MIBG scintigraphy have demonstrated reduced cardiac compared to mediastinal uptake in DLB, as opposed to AD [80-90]. In 2006, Yoshita et al. [84] reported that cardiac MIBG imaging could distinguish between clinically diagnosed DLB and AD with high levels of sensitivity and specificity, findings that have been replicated in 2 recent studies (table 1) [86, 89]. Moreover, MIBG has been found to be more accurate than occipital hypoperfusion using SPECT $[87,91]$ or CSF markers [89] as a means of discriminating between DLB and AD. Interestingly, pathological findings occur even in patients with DLB who have no parkinsonism [84].

If these findings can be confirmed in multicentre studies with large numbers of patients, MIBG scintigraphy may emerge as a useful tool in the early discrimination of DLB from AD. It should be noted, however, that a pathological MIBG scan can be difficult to interpret. Diseases such as diabetes, myocardial infarction, ischaemic heart disease and cardiomyopathy, which are common in the elderly, can damage the post-ganglionic sympathetic neurons, which may lead to false-positive MIBG findings.

\section{Dopamine Transporter Imaging}

One key neuropathological finding in DLB is the loss of dopamine transporter in the caudatum and putamen, which is a marker of loss of dopaminergic neurons in the substantia nigra [92]. Such loss can be detected by dopaminergic PET or SPECT, using ligands specific for the dopamine transporter, such as ${ }^{123} \mathrm{I}-\beta$ CIT and ${ }^{123} \mathrm{I}-\mathrm{FP}-$ CIT, and assessed by visual rating, semi-quantitative and automated quantitative techniques. When used to distinguish PD from essential tremor, dopamine transporter imaging with both ligands has a sensitivity greater than $95 \%$ and a specificity above $80 \%$ [93]. Studies using ${ }^{123}$ IFP-CIT $[94,95]$ and ${ }^{123}$ I- $\beta$ CIT $[96]$ have shown reduced 
Table 1. Sensitivity and specificity of biomarkers for discrimination of DLB and AD

\begin{tabular}{|c|c|c|c|c|c|c|}
\hline \multirow[t]{2}{*}{ Biomarker and reference } & \multirow{2}{*}{$\begin{array}{l}\text { Sensitivity } \\
\%\end{array}$} & \multirow{2}{*}{$\begin{array}{l}\text { Specificity } \\
\%\end{array}$} & \multicolumn{3}{|c|}{ Cases in study } & \multirow[t]{2}{*}{ Comments } \\
\hline & & & DLB & $\mathrm{AD}$ & $\mathrm{NC}$ & \\
\hline \multicolumn{7}{|l|}{ Cerebrospinal fluid } \\
\hline \multirow[t]{2}{*}{ Phospho tau 181p [47] } & 74 & $85^{\mathrm{a}}$ & 60 & 94 & 60 & \multirow{5}{*}{$\begin{array}{l}\text { more favourable sensitivity and } \\
\text { specificity than previous publications } \\
\text { from the same group; the degree of } \\
\text { cohort overlap is unclear }\end{array}$} \\
\hline & 80 & $79^{\mathrm{b}}$ & & & & \\
\hline Ratio a $\beta 1-42$ to a $\beta 1-37[48]$ & 71 & 74 & 21 & 21 & 23 & \\
\hline$A \beta$-ox $[49]$ & 88 & $70^{\mathrm{c}}$ & 21 & 23 & 23 & \\
\hline Total tau and tau/amyloid quotient [46] & not reported & 76 and 71 & 25 & 33 & 46 & \\
\hline \multicolumn{7}{|l|}{ Structural MRI } \\
\hline $\begin{array}{l}\text { Preservation of hippocampus and medial } \\
\text { temporal lobe in DLB compared to AD [65] }\end{array}$ & 38 & 100 & 26 & 28 & 26 & \\
\hline \multicolumn{7}{|l|}{ SPECT } \\
\hline \multicolumn{7}{|c|}{ 99mTc-HMPAO SPECT: occipital hypoperfusion and preserved medial temporal perfusion } \\
\hline Lobotesis et al. [72] & 65 & 87 & 23 & 50 & 20 & \\
\hline Shimizu et al. [73] & 81 & 85 & 36 & 96 & & \multirow[b]{2}{*}{ combined with MMSE } \\
\hline Hanyu et al. [74] & 85 & 85 & 20 & 75 & & \\
\hline \multicolumn{7}{|c|}{ Reduced activity of the striatal dopamine uptake site using ${ }^{123}$ I-FP CIT SPECT } \\
\hline O’Brien et al. [94] & 78 & 94 & 38 & 34 & & \multirow{3}{*}{$\begin{array}{l}\text { multicentre study } \\
\text { pathologically verified diagnosis }\end{array}$} \\
\hline McKeith et al. [99] & 78 & 90 & 151 & 147 & & \\
\hline Walker et al. [97] & 88 & 100 & 27 & 17 & 16 & \\
\hline \multicolumn{7}{|c|}{ Decreased cardiac uptake on MIBG-SPECT: heart-to-mediastinum ratio of MIBG uptake } \\
\hline Wada-Isoe et al. [89] & 100 & 91 & 20 & 32 & 29 & \multirow{3}{*}{$\begin{array}{l}\text { delayed ratio } \\
\text { delayed ratio }\end{array}$} \\
\hline Yoshita et al. [84] & 100 & 100 & 37 & 42 & 10 & \\
\hline Hanyu et al. [86] & 95 & 87 & 32 & 40 & & \\
\hline
\end{tabular}

NC $=$ Normal controls. ${ }^{\text {a }}$ Discriminant analysis. ${ }^{b}$ Classification tree. ${ }^{c}$ DLB vs. all other dementias. ${ }^{\mathrm{d}}$ Uptake is assessed 20 min (early) and $3 \mathrm{~h}$ (delayed) after injection of ${ }^{123}$ I-MIBG.

striatal dopamine transporter uptake in DLB, but not $\mathrm{AD}$, suggesting that this method may be useful in the differential diagnosis of DLB.

Interestingly, an abnormal scan is seen also in patients who have DLB with no or mild parkinsonism [94], a condition that can be particularly difficult to distinguish clinically from AD. Parkinsonism does not occur until more than $80 \%$ of the dopamine nigral neurons have died, but dopamine transporter imaging can potentially identify involvement of the nigro-striatal system at an earlier stage. The usefulness of the test has also been shown in autopsy-proven cases [97], and a decline in binding with time has been demonstrated in longitudinal studies [98]. Of note, dopamine transporter scanning has been shown to have greater accuracy than clinical diagnosis [97].

These early promising findings have been replicated recently in a large multicentre trial using ${ }^{123} \mathrm{I}$-FP-CIT as a ligand [99]. Based on blinded visual reading of scans, the investigators report a sensitivity of $78 \%$ and a specificity of $90 \%$ for probable DLB versus non-DLB dementia (predominantly AD). These results led, in 2006, to approval by the European Agency for the Evaluation of Medicinal Products of FP-CIT SPECT in the differential diagnosis of probable DLB versus AD.

Imaging techniques based on dopamine transporter and other radiotracers can be affected by factors other than the primary biological process under study, so the correspondence between tracer uptake and diagnosis will never be $100 \%$ perfect. Future studies need to explore how dopamine transporter imaging performs in diagnostically uncertain settings and assess whether the test is useful in changing the clinical management of patients and whether it is cost effective. 


\section{Comments and Conclusions}

DLB is a common form of dementia with a more malignant disease course and complicated management than AD. The clinical criteria for DLB have too low a sensitivity, and there is, therefore, a need for a biomarker to increase diagnostic accuracy. According to a consensus report, a biomarker should (1) be able to detect a fundamental feature of the disease; (2) be validated in neuropathologically confirmed cases; (3) be precise, with a specificity of $75-85 \%$ or greater; (4) be non-invasive; (5) be simple to perform, and (6) inexpensive [100]. A wide range of potential biomarkers for DLB exists, and promising results have been reported in studies of CSF protein analyses, structural MRI and perfusion SPECT. Several small, single-centre studies using scintigraphy with ${ }^{123}$ I-MIBG, a measure of post-ganglionic sympathetic innervation, have demonstrated reduced cardiac compared to mediastinal uptake in DLB, as opposed to $\mathrm{AD}$, with excellent sensitivity and specificity. To date, the most compelling evidence has come from visualisation of striatal dopamine transporter activity, using ${ }^{123} \mathrm{I}$-FP-CIT. This marker has demonstrated high sensitivity and specificity in a large multi-centre trial and in a small study with pathological confirmation of diagnosis, supporting the usefulness of this test in distinguishing DLB from AD. Future work, using modern techniques, will hopefully provide novel, accurate and less expensive biomarkers and explore whether a combination of different biomarkers can improve diagnostic accuracy.

\section{Acknowledgements}

This work was supported by an unrestricted educational grant from GE Healthcare, who otherwise had no input. D.A. has previously received honoraria from GE Healthcare for speaking and attending advisory boards. He and C.B. have received support from Novartis, Pfizer, Janssen-Cilag and H Lundbeck. C.B. has also received support from Bayer.

\section{References}

1 McKeith I, Mintzer I, Aarsland D, Burn D, Chiu H, Cohen-Mansfield J, Dickson D, Dubois B, Duda JE, Feldman H, Gauthier S, Halliday G, Lawlor B, Lippa C, Lopez OL, Carlos Machado J, O’Brien J, Playfer J, Reid W; International Psychogeriatric Association Expert Meeting on DLB: Dementia with Lewy bodies. Lancet Neurol 2004;3:19-28.

-2 Wakisaka Y, Furuta A, Tanizaki Y, Kiyohara Y, Iida M, Iwaki T: Age-associated prevalence and risk factors of Lewy body pathology in a general population: the Hisayama study. Acta Neuropathol 2003;106:374-382.

-3 Zaccai J, McCracken C, Brayne C: A systematic review of prevalence and incidence studies of dementia with Lewy bodies. Age Ageing 2005;34:561-566.

-4 Lippa CF, Duda JF, Grossman M, Hurtig HI, Aarsland D, Boeve BF, Brooks DJ, Dickson DW, Dubois B, Emre M, Fahn S, Farmer JM, Galasko D, Galvin JE, Goetz CG, Growdon JH, Gwinn-Hardy KA, Hardy J, Heutink P, Iwatsubo T, Kosaka K, Lee VM, Leverenz JB, Masliah E, McKeith IG, Nussbaum RL, Olanow CW, Ravina BM, Singleton AB, Tanner CM, Trojanowski JQ, Wszolek ZK; DLB/ PDD Working Group: DLB and PDD boundary issues: diagnosis, treatment, molecular pathology, and biomarkers. Neurology 2007; 68:812-819.

5 Aarsland D, Zaccai J, Brayne C: A systematic review of prevalence studies of dementia in Parkinson's disease. Mov Disord 2005;20: 1255-1263.
6 McKeith IG, Galasko D, Kosaka K, Perry EK, Dickson DW, Hansen LA, Salmon DP, Lowe J, Mirra SS, Byrne EJ, Lennox G, Quinn NP, Edwardson JA, Ince PG, Bergeron C, Burns A, Miller BL, Lovestone S, Collerton D, Jansen EN, Ballard C, de Vos RA, Wilcock GK, Jellinger KA, Perry RH: Consensus guidelines for the clinical and pathologic diagnosis of dementia with Lewy bodies (DLB): report of the consortium on DLB international workshop. Neurology 1996;47:1113-1124.

7 McKeith IG, Dickson DW, Lowe J, Emre M, O’Brien JT, Feldman H, Cummings J, Duda JE, Lippa C, Perry EK, Aarsland D, Arai H, Ballard CG, Boeve B, Burn DJ, Costa D, Del Ser T, Dubois B, Galasko D, Gauthier S, Goetz CG, Gomez-Tortosa E, Halliday G, Hansen LA, Hardy J, Iwatsubo T, Kalaria RN, Kaufer D, Kenny RA, Korczyn A, Kosaka K, Lee VM, Lees A, Litvan I, Londos E, Lopez OL, Minoshima S, Mizuno Y, Molina JA, Mukaetova-Ladinska EB, Pasquier F, Perry RH, Schulz JB, Trojanowski JQ, Yamada M; Consortium on DLB: Diagnosis and management of dementia with Lewy bodies: third report of the DLB Consortium. Neurology 2005;65:1863-1872.

$\checkmark 8$ Mega MS, Masterman DL, Benson DF, Vinters HV, Tomiyasu U, Craig AH, Foti DJ, Kaufer D, Scharre DW, Fairbanks L, Cummings JL: Dementia with Lewy bodies: reliability and validity of clinical and pathologic criteria. Neurology 1996;47:1403-1409.
-9 Ferman TJ, Smith GE, Boeve BF, Ivnik RJ, Petersen RC, Knopman D, Graff-Radford N, Parisi J, Dickson DW: DLB fluctuations: specific features that reliably differentiate DLB from AD and normal aging. Neurology 2004; 62:181-187.

10 Fahn S, Elton RL; UPDRS Development Committee: Unified Parkinson's Disease Rating Scale; in Fahn S, Marsden CD, Calne DB, Goldstein M (eds): Recent developments in Parkinson's disease. Florham Park, Macmillan Health Care Information, 1987, vol 2, pp 153-164.

11 Richards M, Marder K, Bell K, Dooneief G, Mayeux R, Stern Y: Interrater reliability of extrapyramidal signs in a group assessed for dementia. Arch Neurol 1991;48:1147-1149.

12 Ballard C, McKeith I, Burn D, Harrison R, O’Brien J, Lowery K, Campbell M, Perry R, Ince P: The UPDRS scale as a means of identifying extrapyramidal signs in patients suffering from dementia with Lewy bodies. Acta Neurol Scand 1997;96:366-371.

13 Ballard CG, Jacoby R, Del Ser T, Khan MN, Munoz DG, Holmes C, Nagy Z, Perry EK, Joachim C, Jaros E, O’Brien JT, Perry RH, McKeith IG: Neuropathological substrates of psychiatric symptoms in prospectively studied patients with autopsy-confirmed dementia with lewy bodies. Am J Psychiatry 2004;161:843-849. 
-14 Waldemar G, Dubois B, Emre M, Georges J, McKeith IG, Rossor M, Scheltens P, Tariska P, Winblad B; EFNS: Recommendations for the diagnosis and management of Alzheimer's disease and other disorders associated with dementia: EFNS guideline. Eur J Neurol 2007;14:e1-e26.

15 McKeith I, Fairbairn A, Perry R, Thompson P, Perry E: Neuroleptic sensitivity in patients with senile dementia of Lewy body type. BMJ 1992;305:673-678.

-16 Aarsland D, Perry R, Larsen JP, McKeith IG, O'Brien JT, Perry EK, Burn D, Ballard CG: Neuroleptic sensitivity in Parkinson's disease and parkinsonian dementias. J Clin Psychiatry 2005;66:633-637.

17 Molloy SA, Rowan EN, O’Brien JT, McKeith IG, Wesnes K, Burn DJ: Effect of levodopa on cognitive function in Parkinson's disease with and without dementia and dementia with Lewy bodies. J Neurol Neurosurg Psychiatry 2006;77:1323-1328.

-18 McKeith IG, Rowan E, Askew K, Naidu A, Allan L, Barnett N, Lett D, Mosimann UP, Burn D, O’Brien JT: More severe functional impairment in dementia with Lewy bodies than Alzheimer disease is related to extrapyramidal motor dysfunction. Am J Geriatr Psychiatry 2006;14:582-588.

19 Bostrom FMP, Jonsson L, Minthon L, Londos E: Patients with dementia with Lewy bodies have more impaired quality of life than patients with Alzheimer's disease. Neurodegener Dis 2007;4:127.

20 Williams MM, Xiong C, Morris JC, Galvin JE: Survival and mortality differences between dementia with Lewy bodies vs. Alzheimer disease. Neurology 2006;67:19351941.

21 Bostrom F, Jonsson L, Minthon L, Londos E: Patients with Lewy body dementia use more resources than those with Alzheimer's disease. Int J Geriatr Psychiatry 2006, E-pub ahead of print. DOI: $10.1002 / \mathrm{gps} .1738$.

-22 McNaught KS, Perl $\overline{\mathrm{DP}, \text { Brownell AL}}$, Olanow CW: Systemic exposure to proteasome inhibitors causes a progressive model of Parkinson's disease. Ann Neurol 2004;56:149162.

-23 Crystal HA, Dickson DW, Lizardi JE, Davies P, Wolfson LI: Antemortem diagnosis of diffuse Lewy body disease. Neurology 1990;40: 1523-1528.

-24 Calzetti S, Bortone E, Negrotti A, Zinno L, Mancia D: Frontal intermittent rhythmic delta activity (FIRDA) in patients with dementia with Lewy bodies: a diagnostic tool? Neurol Sci 2002;23(suppl 2):S65-S66.

-25 Briel RC, McKeith IG, Barker WA, Hewitt Y, Perry RH, Ince PG, Fairbairn AF: EEG findings in dementia with Lewy bodies and Alzheimer's disease. J Neurol Neurosurg Psychiatry 1999;66:401-403.

-26 Barber PA, Varma AR, Lloyd JJ, Haworth B, Snowden JS, Neary D: The electroencephalogram in dementia with Lewy bodies. Acta Neurol Scand 2000; 101:53-56.
27 Londos E, Passant U, Brun A, Rosén I, Risberg J, Gustafson L: Regional cerebral blood flow and EEG in clinically diagnosed dementia with Lewy bodies and Alzheimer's disease. Arch Gerontol Geriatr 2003;36:231245.

28 Kai T, Asai Y, Sakuma K, Koeda T, Nakashima K: Quantitative electroencephalogram analysis in dementia with Lewy bodies and Alzheimer's disease. J Neurol Sci 2005;237: 89-95.

29 Walker MP, Ayre GA, Perry EK, Wesnes K, McKeith IG, Tovee M, Edwardson JA, Ballard CG: Quantification and characterization of fluctuating cognition in dementia with Lewy bodies and Alzheimer's disease. Dement Geriatr Cogn Disord 2000;11:327335.

30 Walker MP, Ayre GA, Cummings JL, Wesnes K, McKeith IG, O’Brien JT, Ballard CG: Quantifying fluctuation in dementia with Lewy bodies, Alzheimer's disease, and vascular dementia. Neurology 2000;54:16161625.

31 Hardy J, Cai H, Cookson MR, Gwinn-Hardy K, Singleton A: Genetics of Parkinson's disease and parkinsonism. Ann Neurol 2006; 60:389-398.

32 Blennow K, de Leon MJ, Zetterberg H: Alzheimer's disease. Lancet 2006;368:387-403.

33 Kurz MW, Larsen JP, Kvaloy JT, Aarsland D: Associations between family history of Parkinson's disease and dementia and risk of dementia in Parkinson's disease: a communitybased, longitudinal study. Mov Disord 2006; 21:2170-2174.

34 Woodruff BK, Graff-Radford NR, Ferman TJ, Dickson DW, DeLucia MW, Crook JE, Arvanitakis Z, Brassler S, Waters C, Barker W, Duara R: Family history of dementia is a risk factor for Lewy body disease. Neurology 2006;66:1949-1950.

35 McKeith IG: Consensus guidelines for the clinical and pathologic diagnosis of dementia with Lewy bodies (DLB): report of the Consortium on DLB International Workshop. J Alzheimers Dis 2006;9:417-423.

36 Aarsland D, Perry R, Brown A, Larsen JP, Ballard C: Neuropathology of dementia in Parkinson's disease: a prospective, communitybased study. Ann Neurol 2005;58:773-776.

37 Wszolek ZK, Pfeiffer RF, Tsuboi Y, Uitti RJ, McComb RD, Stoessl AJ, Strongosky AJ, Zimprich A, Müller-Myhsok B, Farrer MJ, Gasser T, Calne DB, Dickson DW: Autosomal dominant parkinsonism associated with variable synuclein and tau pathology. Neurology 2004;62:1619-1622.

38 Zimprich A, Biskup S, Leitner P, Lichtner P, Farrer M, Lincoln S, Kachergus J, Hulihan M, Uitti RJ, Calne DB, Stoessl AJ, Pfeiffer RF, Patenge N, Carbajal IC, Vieregge P, Asmus F, Müller-Myhsok B, Dickson DW, Meitinger T, Strom TM, Wszolek ZK, Gasser T: Mutations in LRRK2 cause autosomal-dominant parkinsonism with pleomorphic pathology. Neuron 2004;44:601-607.
39 Berg D, Schweitzer K, Leitner P, Zimprich A, Lichtner P, Belcredi P, Brussel T, Schulte C, Maass S, Nagele T: Type and frequency of mutations in the LRRK2 gene in familial and sporadic Parkinson's disease. Brain 2005; 128:3000-3011.

40 Zhu X, Babar A, Siedlak SL, Yang Q, Ito G, Iwatsubo T, Smith MA, Perry G, Chen SG: LRRK2 in Parkinson's disease and dementia with Lewy bodies. Mol Neurodegener 2006; $1: 17$.

41 Mayeux R, Saunders AM, Shea S, Mirra S, Evans D, Roses AD, Hyman BT, Crain B, Tang MX, Phelps CH; Alzheimer's Disease Centers Consortium on Apolipoprotein E and Alzheimer's Disease: Utility of the apolipoprotein E genotype in the diagnosis of Alzheimer's disease. N Engl J Med 1998;338: 506-511.

42 Borroni B, Grassi M, Costanzi C, Archetti S, Caimi L, Padovani A: APOE genotype and cholesterol levels in Lewy body dementia and Alzheimer disease: investigating genotype-phenotype effect on disease risk. Am J Geriatr Psychiatry 2006;14:1022-1031.

43 Singleton AB, Wharton A, O’Brien KK, Walker MP, McKeith IG, Ballard CG, O’Brien J, Perry RH, Ince PG, Edwardson JA, Morris CM: Clinical and neuropathological correlates of apolipoprotein E genotype in dementia with Lewy bodies. Dement Geriatr Cogn Disord 2002;14:167-175.

44 Engelborghs S, Dermaut B, Goeman J, Saerens J, Mariën P, Pickut BA, Van den Broeck M, Serneels S, Cruts M, Van Broeckhoven C, De Deyn PP: Prospective Belgian study of neurodegenerative and vascular dementia: APOE genotype effects. J Neurol Neurosurg Psychiatry 2003;74:1148-1151.

45 Hansson O, Zetterberg H, Buchhave P, Londos E, Blennow K, Minthon L: Association between CSF biomarkers and incipient Alzheimer's disease in patients with mild cognitive impairment: a follow-up study. Lancet Neurol 2006;5:228-234.

46 Gómez-Tortosa E, Gonzalo I, Fanjul S, Sainz MJ, Cantarero S, Cemillán C, Yébenes JG, del Ser T: Cerebrospinal fluid markers in dementia with Lewy bodies compared with Alzheimer disease. Arch Neurol 2003;60: 1218-1222.

47 Vanderstichele H, De Vreese K, Blennow K, Andreasen N, Sindic C, Ivanoiu A, Hampel H, Bürger K, Parnetti L, Lanari A, Padovani A, DiLuca M, Bläser M, Olsson AO, Pottel H, Hulstaert F, Vanmechelen E: Analytical performance and clinical utility of the INNOTEST PHOSPHO-TAU181P assay for discrimination between Alzheimer's disease and dementia with Lewy bodies. Clin Chem Lab Med 2006;44:1472-1480. 
-48 Bibl M, Mollenhauer B, Esselmann H, Lewczuk P, Klafki HW, Sparbier K, Smirnov A, Cepek L, Trenkwalder C, Rüther E, Kornhuber J, Otto M, Wiltfang J: CSF amyloid-betapeptides in Alzheimer's disease, dementia with Lewy bodies and Parkinson's disease dementia. Brain 2006;129:1177-1187.

-49 Bibl M, Mollenhauer B, Lewczuk P, Esselmann H, Wolf S, Trenkwalder C, Otto M, Stiens G, Rüther E, Kornhuber J, Wiltfang J: Validation of amyloid-beta peptides in CSF diagnosis of neurodegenerative dementias. Mol Psychiatry 2007;12:671-680.

-50 Clark CM, Xie S, Chittams J, Ewbank D, Peskind E, Galasko D, Morris JC, McKeel DW, Farlow M, Weitlauf SL, Quinn J, Kaye J, Knopman D, Arai H, Doody RS, De Carli C, Leight S, Lee VM, Trojanowski JQ: Cerebrospinal fluid tau and beta-amyloid: how well do these biomarkers reflect autopsy-confirmed dementia diagnoses? Arch Neurol 2003;60:1696-1702.

-51 Mollenhauer B, Cepek L, Bibl M, Wiltfang J, Schulz-Schaeffer WJ, Ciesielczyk B, Neumann M, Steinacker P, Kretzschmar HA, Poser S, Trenkwalder C, Otto M: Tau protein, Abeta42 and S-100B protein in cerebrospinal fluid of patients with dementia with Lewy bodies. Dement Geriatr Cogn Disord 2005;19:164-170.

52 Mollenhauer B, Bibl M, Wiltfang J, Steinacker P, Ciesielczyk B, Neubert K, Trenkwalder C, Otto M: Total tau protein, phosphorylated tau (181p) protein, betaamyloid(1-42), and beta-amyloid(1-40) in cerebrospinal fluid of patients with dementia with Lewy bodies. Clin Chem Lab Med 2006;44:192-195

-53 El-Agnaf OM, Salem SA, Paleologou KE, Curran MD, Gibson MJ, Court JA, Schlossmacher MG, Allsop D: Detection of oligomeric forms of alpha-synuclein protein in human plasma as a potential biomarker for Parkinson's disease. FASEB J 2006;20:419425.

54 Tokuda T, Salem SA, Allsop D, Mizuno T, Nakagawa M, Qureshi MM, Locascio JJ, Schlossmacher MG, El-Agnaf OM: Decreased alpha-synuclein in cerebrospinal fluid of aged individuals and subjects with Parkinson's disease. Biochem Biophys Res Commun 2006;349:162-166.

-55 Mollenhauer B, Trenkwalder C, Cullen V, Krastins, B, Kahn I, El-Agnaf OAA, Locascio JJ, Kretzchmar HA, Sarracino D, Von Sattel JP, Schlossmacher MG: A platform for the quantification of alpha-synuclein in cerebrospinal fluid: evidence for a potential biomarker for synucleinopathies. Neurodegener Dis 2007;4:156.

56 Schlossmacher MG: Quantification of alpha-synuclein in dopamine cells, peripheral blood, genotyped brain and CSF. Neurodegener Dis 2007;4:187.
Shukla R, Rajani M, Srivastava N, Barthwal MK, Dikshit M: Nitrite and malondialdehyde content in cerebrospinal fluid of patients with Parkinson's disease. Int J Neurosci 2006;116:1391-1402.

58 Waragai M, Wei J, Fujita M, Nakai M, Ho GJ, Masliah E, Akatsu H, Yamada T, Hashimoto MW: Increased level of DJ-1 in the cerebrospinal fluids of sporadic Parkinson's disease. Biochem Biophys Res Comm 2006;345:967972.

59 Isobe C, Murata T, Sato C, Terayama Y: Increase of total homocysteine concentration in cerebrospinal fluid in patients with $\mathrm{Alz}$ heimer's disease and Parkinson's disease. Life Sci 2005;77:1836-1843.

60 Hashimoto M, Rockenstein E, Crews L, Masliah E: Role of protein aggregation in mitochondrial dysfunction and neurodegeneration in Alzheimer's and Parkinson's diseases. Neuromolecular Med 2003;4:21-36.

61 Hyun DH, Lee M, Halliwell B, Jenner P: Proteasomal inhibition causes the formation of protein aggregates containing a wide range of proteins, including nitrated proteins. J Neurochem 2003;86:363-373.

62 Abdi F, Quinn JF, Jankovic J, McIntosh M, Leverenz JB, Peskind E, Nixon R, Nutt J, Chung K, Zabetian C, Samii A, Lin M, Hat$\tan$ S, Pan C, Wang Y, Jin J, Zhu D, Li GJ, Liu Y, Waichunas D, Montine TJ, Zhang J: Detection of biomarkers with a multiplex quantitative proteomic platform in cerebrospinal fluid of patients with neurodegenerative disorders. J Alzheimer Dis 2006;9:293-348.

63 Gao FQ, Black SE, Leibovitch FS, Callen DJ, Rockel CP, Szalai JP: Linear width of the medial temporal lobe can discriminate Alzheimer's disease from normal aging: the Sunnybrook dementia study. Neurobiol Aging 2004;25:441-448.

64 Burton EJ, Karas G, Paling SM, Barber R, Williams ED, Ballard CG, McKeith IG, Scheltens P, Barkhof F, O’Brien JT: Patterns of cerebral atrophy in dementia with Lewy bodies using voxel-based morphometry. Neuroimage 2002;17:618-630.

65 Barber R, Gholkar A, Scheltens P, Ballard C, McKeith IG, O’Brien JT: Medial temporal lobe atrophy on MRI in dementia with Lewy bodies. Neurology 1999;52:1153-1158.

66 Barber R, Ballard C, McKeith IG, Gholkar A, O'Brien JT: MRI volumetric study of dementia with Lewy bodies: a comparison with AD and vascular dementia. Neurology 2000;54: 1304-1309.

67 Cousins DA, Burton EJ, Burn D, Gholkar A, McKeith IG, O'Brien JT: Atrophy of the putamen in dementia with Lewy bodies but not Alzheimer's disease: an MRI study. Neurology 2003;61:1191-1195.

68 Brenneis C, Wenning GK, Egger KE, Schocke M, Trieb T, Seppi K, Marksteiner J, Ransmayr G, Benke T, Poewe W: Basal forebrain atrophy is a distinctive pattern in dementia with Lewy bodies. Neuroreport 2004; 15: 1711-1714.
69 Hanyu H, Shimizu S, Tanaka Y, Hirao K, Iwamoto T, Abe K: MR features of the substantia innominata and therapeutic implications in dementias. Neurobiol Aging 2007; 28:548-554.

70 O’Brien JT, Paling S, Barber R, Williams ED, Ballard C, McKeith IG, Gholkar A, Crum WR, Rossor MN, Fox NC: Progressive brain atrophy on serial MRI in dementia with Lewy bodies, AD, and vascular dementia. Neurology 2001;56:1386-1388.

71 Whitwell JL, Weigand SD, Shiung MM, Boeve BF, Ferman TJ, Smith GE, Knopman DS, Petersen RC, Benarroch EE, Josephs KA, Jack CR: Focal atrophy in dementia with Lewy bodies on MRI: a distinct pattern from Alzheimer's disease. Brain 2007;130:708719 .

72 Lobotesis K, Fenwick JD, Phipps A, Ryman A, Swann A, Ballard C, McKeith IG, O’Brien JT: Occipital hypoperfusion on SPECT in dementia with Lewy bodies but not AD. Neurology 2001;56:643-649.

73 Shimizu S, Hanyu H, Kanetaka H, Iwamoto T, Koizumi K, Abe K: Differentiation of dementia with Lewy bodies from Alzheimer's disease using brain SPECT. Dement Geriatr Cogn Disord 2005;20:25-30.

74 Hanyu H, Shimizu S, Hirao K, Kanetaka H, Sakurai H, Iwamoto T, Koizumi K, Abe K: Differentiation of dementia with Lewy bodies from Alzheimer's disease using MiniMental State Examination and brain perfusion SPECT. J Neurol Sci 2006;250:97-102.

75 Kemp PM, Hoffmann SA, Tossici-Bolt L, Fleming JS, Holmes C: Limitations of the HMPAO SPECT appearances of occipital lobe perfusion in the differential diagnosis of dementia with Lewy bodies. Nucl Med Commun 2007;28:451-456.

76 Kemp PM, Holmes C: Imaging in dementia with Lewy bodies: a review. Nucl Med Commun 2007;28:511-519.

77 Allan LM, Ballard CG, Allen J, Murray A, Davidson AW, McKeith IG, Kenny RA: Autonomic dysfunction in dementia. J Neurol Neurosurg Psychiatry 2007;78:671-677.

78 Orimo S, Amino T, Itoh Y, Takahashi A, Kojo T, Uchihara T, Tsuchiya K, Mori F, Wakabayashi K, Takahashi $\mathrm{H}$ : Cardiac sympathetic denervation precedes neuronal loss in the sympathetic ganglia in Lewy body disease. Acta Neuropathol (Berl) 2005;109:583588.

79 Spiegel J, Möllers MO, Jost WH, Fuss G, Samnick S, Dillmann U, Becker G, Kirsch CM: FP-CIT and MIBG scintigraphy in early Parkinson's disease. Mov Disord 2005;20: 552-561.

80 Watanabe H, Ieda T, Katayama T, Takeda A, Aiba I, Doyu M, Hirayama M, Sobue G: Cardiac $^{123}$ I-meta-iodobenzylguanidine (MIBG) uptake in dementia with Lewy bodies: comparison with Alzheimer's disease. J Neurol Neurosurg Psychiatry 2001;70:781-783. 
81 Yoshita M, Taki J, Yamada M: A clinical role for $\left.{ }^{123} \mathrm{I}\right]$ MIBG myocardial scintigraphy in the distinction between dementia of the Alzheimer type and dementia with Lewy bodies. J Neurol Neurosurg Psychiatry 2001; 71:583-588.

-82 Oide T, Tokuda T, Momose M, Oguchi K, Nakamura A, Ohara S, Ikeda S: Usefulness of $\left[{ }^{123} \mathrm{I}\right]$ metaiodobenzylguanidine ([ $\left.\left.{ }^{123} \mathrm{I}\right] \mathrm{MIBG}\right)$ myocardial scintigraphy in differentiating between Alzheimer's disease and dementia with Lewy bodies. Intern Med 2003;42:686-690.

-83 Jindahra P, Vejjajiva A, Witoonpanich R, Sirisriro R, Sritara C, Pulkes T: Differentiation of dementia with Lewy bodies, Alzheimer's disease and vascular dementia by cardiac ${ }^{131} \mathrm{I}$-meta-iodobenzylguanidine (MIBG) uptake (preliminary report). J Med Assoc Thai 2004;87:1176-1181.

-84 Yoshita M, Taki J, Yokoyama K, NoguchiShinohara M, Matsumoto Y, Nakajima K, Yamada M: Value of ${ }^{123}$ I-MIBG radioactivity in the differential diagnosis of DLB from AD. Neurology 2006;66:1850-1854.

-85 Kashihara K, Ohno M, Kawada S, Okumura Y: Reduced cardiac uptake and enhanced washout of ${ }^{123}$ I-MIBG in pure autonomic failure occurs conjointly with Parkinson's disease and dementia with Lewy bodies. J Nucl Med 2006;47:1099-1101.

-86 Hanyu H, Shimizu S, Hirao K, Sakurai H, Iwamoto T, Chikamori T, Hida S, Yamashina A, Koizumi K, Abe K: The role of ${ }^{123} \mathrm{I}$-metaiodobenzylguanidine myocardial scintigraphy in the diagnosis of Lewy body disease in patients with dementia in a memory clinic. Dement Geriatr Cogn Disord 2006;22: 379-384.

87 Hanyu H, Shimizu S, Hirao K, Kanetaka H, Iwamoto T, Chikamori T, Usui Y, Yamashina A, Koizumi K, Abe K: Comparative value of brain perfusion SPECT and $\left[{ }^{123} \mathrm{I}\right] \mathrm{MIBG}$ myocardial scintigraphy in distinguishing between dementia with Lewy bodies and Alzheimer's disease. Eur J Nucl Med Mol Imaging 2006;33:248-253.
-88 Suzuki M, Kurita A, Hashimoto M, Fukumitsu N, Abo M, Ito Y, Urashima M, Inoue $\mathrm{K}$ : Impaired myocardial ${ }^{123} \mathrm{I}$-metaiodobenzylguanidine uptake in Lewy body disease: comparison between dementia with Lewy bodies and Parkinson's disease. J Neurol Sci 2006;240:15-19.

89 Wada-Isoe K, Kitayama M, Nakaso K, Nakashima K: Diagnostic markers for diagnosing dementia with Lewy bodies: CSF and MIBG cardiac scintigraphy study. J Neurol Sci 2007;260:33-37.

90 Oka H, Morita M, Onouchi K, Yoshioka M, Mochio S, Inoue K: Cardiovascular autonomic dysfunction in dementia with Lewy bodies and Parkinson's disease. J Neurol Sci 2007;254:72-77.

91 Yoshita M, Yamada M: Occipital cerebral hypoperfusion and cardiac sympathetic dysfunction in dementia with Lewy bodies and dementia of the Alzheimer type. Neurology 2003;60:A208.

92 Piggott MA, Marshall EF, Thomas N, Lloyd $S$, Court JA, Jaros E, Burn D, Johnson M, Perry $\mathrm{RH}$, McKeith IG, Ballard C, Perry EK: Striatal dopaminergic markers in dementia with Lewy bodies, Alzheimer's and Parkinson's diseases: rostrocaudal distribution. Brain 1999;122:1449-1468.

93 Benamer TS, Patterson J, Grosset DG, Booij J, de Bruin K, van Royen E, Speelman JD, Horstink MH, Sips HJ, Dierckx RA, Versijpt J, Decoo D, Van Der Linden C, Hadley DM, Doder M, Lees AJ, Costa DC, Gacinovic S, Oertel WH, Pogarell O, Hoeffken H, Joseph K, Tatsch K, Schwarz J, Ries V: Accurate differentiation of parkinsonism and essential tremor using visual assessment of $\left[{ }^{123} \mathrm{I}\right]-\mathrm{FP}-$ CIT SPECT imaging: the $\left[{ }^{123} \mathrm{I}\right]-\mathrm{FP}-\mathrm{CIT}$ study group. Mov Disord 2000;15:503-510.

94 O’Brien JT, Colloby S, Fenwick J, Williams ED, Firbank M, Burn D, Aarsland D, McKeith IG: Dopamine transporter loss visualized with FP-CIT SPECT in the differential diagnosis of dementia with Lewy bodies. Arch Neurol 2004;61:919-925. $\checkmark 95$ Walker Z, Costa DC, Walker RW, Shaw K, Gacinovic S, Stevens T, Livingston G, Ince P, McKeith IG, Katona CL: Differentiation of dementia with Lewy bodies from Alzheimer's disease using a dopaminergic presynaptic ligand. J Neurol Neurosurg Psychiatry 2002;73:134-140.

96 Donnemiller E, Heilmann J, Wenning GK, Berger W, Decristoforo C, Moncayo R, Poewe W, Ransmayr G: Brain perfusion scintigraphy with 99mTc-HMPAO or 99mTc-ECD and ${ }^{123}$ I-beta-CIT single-photon emission tomography in dementia of the Alzheimer type and diffuse Lewy body disease. Eur J Nucl Med 1997;24:320-325.

$\checkmark 97$ Walker Z, Jaros E, Walker RW, Lee L, Costa DC, Livingston G, Ince P, Perry R, McKeith I, Katona CL: Dementia with Lewy bodies: a comparison of clinical diagnosis, FP-CIT SPECT imaging and autopsy. J Neurol Neurosurg Psychiatry 2007;78:1176-1181.

$\checkmark 98$ Colloby SJ, Williams ED, Burn DJ, Lloyd JJ, McKeith IG, O'Brien JT: Progression of dopaminergic degeneration in dementia with Lewy bodies and Parkinson's disease with and without dementia assessed using ${ }^{123} \mathrm{I}-$ FP-CIT SPECT. Eur J Nucl Med Mol Imaging 2005;32:1176-1185.

$\checkmark 99$ McKeith I, O’Brien J, Walker Z, Tatsch K, Booij J, Darcourt J, Padovani A, Giubbini R, Bonuccelli U, Volterrani D, Holmes C, Kemp P, Tabet N, Meyer I, Reininger C; DLB Study Group: Sensitivity and specificity of dopamine transporter imaging with ${ }^{123}$ I-FP-CIT SPECT in dementia with Lewy bodies: a phase III, multicentre study. Lancet Neurol 2007;6:305-313.

100 Ronald and Nancy Reagan Research Institute of the Alzheimer's Association and the National Institute on Aging Working Group: Consensus report of the Working Group on: Molecular and Biochemical Markers of Alzheimer's Disease. Neurobiol Aging 1998;19:109-116. 